Research Article

\title{
Equivalent Test Method for Strong Electromagnetic Field Radiation Effect of EED
}

\author{
Biao Wang $\mathbb{D},{ }^{1}$ Yongwei Sun $\mathbb{D}^{2},{ }^{2}$ Xuetian Wang, ${ }^{1}$ Guanghui Wei, ${ }^{2}$ and Hongmin Gao ${ }^{1}$ \\ ${ }^{1}$ Department of School of Information and Electronics, Beijing Institute of Technology, 100081 Beijing, China \\ ${ }^{2}$ National Key Laboratory on Electromagnetic Environment Effects, Shijiazhuang Campus of Army Engineering University, \\ 050003 Shijiazhuang, China \\ Correspondence should be addressed to Biao Wang; wangbiao0319@126.com and Yongwei Sun; syw3369@sina.com
}

Received 12 August 2021; Revised 28 September 2021; Accepted 15 October 2021; Published 8 November 2021

Academic Editor: Miguel Ferrando Bataller

Copyright (c) 2021 Biao Wang et al. This is an open access article distributed under the Creative Commons Attribution License, which permits unrestricted use, distribution, and reproduction in any medium, provided the original work is properly cited.

\begin{abstract}
The present study proposed the equivalent test method for the strong electromagnetic field radiation of electric explosive devices (EEDs) of the weapon equipment to satisfy the military requirements of the electromagnetic radiation safety test, as well as the evaluation of the electric ignition, the electric initiation ammunition, or missiles. Under stable conditions, the ignition excitation test and the bridge wire temperature increase test were performed to determine the ignition temperature of the EED. As radiated by the strong electromagnetic field, the relationship between the temperature increase of the bridge wire and the electric field intensity of the EED was developed based on the theoretical analysis and the experimental test. Given the ignition temperature of the EED, the radiation field intensity of the EED at 50\% ignition was determined. As compared with the $50 \%$ ignition field intensity of the EED directly radiated by the strong electromagnetic field, an error less than $1 \mathrm{~dB}$ was caused. On that basis, the correctness of the equivalent test method was verified. Accordingly, this method was suggested to act as an effective method and technical means to test and evaluate the electromagnetic radiation safety of ammunition and missiles in unfavorable electromagnetic environments.
\end{abstract}

\section{Introduction}

The EED is recognized as the electric initiator or the components that exploit electric energy to detonate and ignite the explosives, the propellants, or the pyrotechnic materials within the device [1]. To be specific, such a device consists of EED, conductive explosive synthetic detonator, semiconductor bridge electric exploding device, laser exploding device, etc. [2-5]. The EED has been commonly employed to ignite gunpowder and detonate explosives, and it can also act as a small driving device for rapid valve opening, arming, and rocket separation [6-9]. It achieves the extensive applications in several military projects (e.g., conventional weapons, ammunition, missiles, nuclear weapons, and aerospace systems). In addition, it is the most sensitive initiating energy for the initiation and the ignition. Moreover, its position and role in weapon systems are determined by its function and sensitivity. Its safety and reliability can directly impact the safety and reliability of weapon systems [10-18].

The EED exhibits the sensitivity to electromagnetic energy. In addition, its accidental ignition is likely to cause the effect of the whole weapon system and bring great losses. Its design should abide by the electromagnetic safety requirements of various EEDs [19-26]. To guide equipment design, production, and effect experimental evaluation, the U.S. military has formulated a range of standards and specifications. As stipulated by "Safety Criteria for Munition Rocket and Missile Motor Ignition System Design: Safety Criteria" MIL-STD-1901A and "Safety Criteria for fuze Design" MIL-STD-1316D design, the EED and fuzes should not start and ignite accidentally during and after the following environmental exposure processes within the normal life cycle (e.g., electromagnetic radiation, electrostatic discharge, electromagnetic pulse, electromagnetic interference, lightning action, or power supply transient) [27, 28]. 
Moreover, the ignition system and the fuze should be capable of operating safely during and after the exposure to the mentioned environment.

Furthermore, the Chinese army is constantly modifying the relevant standards and requirements for electromagnetic environmental effects of equipment. In accordance with "Electromagnetic compatibility requirements for systems" GJB 1389A-2005", the external electromagnetic environment of electromagnetic radiation harm imposed on EEDs exhibits the frequency range of $10 \mathrm{kHz} \sim 45 \mathrm{GHz}$, and the maximum peak field strength is $27460 \mathrm{~V} / \mathrm{m}$ [29]. "Test method for hazards of electromagnetic radiation to ordnance" GJB 7504-2012 stipulates the test method for the ability of EED in ordnance to withstand electromagnetic radiation within its service life, which is achieved by primarily measuring the induced current, voltage, or power of the EED in the tested ordnance to assess the safety of the EED under the electromagnetic radiation [30]. The test method to measure the induced current, voltage, or power cannot effectively evaluate the electromagnetic safety test of the EED under microwave radiation. Under the radiation frequency exceeding $\mathrm{GHz}$, the induced current will form a standing wave distribution on the lead wire of the EED, and the current amplitude at different positions will be altered noticeably [31]. As impacted by the measuring probe, bridge wire thickness, and lead electromagnetic induction, the induced current at the bridge wire position is difficult to be accurately measured; besides, under skin effect, the bridge wire resistance and ignition current change with frequency, and its electromagnetic safety cannot be accurately evaluated [32-36]. Wang et al. introduced the test method of ignition temperature of EED under electromagnetic pulse in a recently published article [37], but there is no paper published to study the strong field equivalent test method of EED under continuous wave by temperature measurement.

In this paper, the EED was taken as the research object. According to the requirements of the weapon system for the high power and high field electromagnetic radiation effect test, the equivalent test method of the high field electromagnetic environment effect is proposed. Through the theoretical analysis, the relationships between the temperature rise of the bridge wire and the injection current and the temperature rise of the bridge wire and the radiation field strength were developed, respectively. Through the steady current injection effect test in the steady environment, the $50 \%$ ignition current of the EED was determined. The temperature sensor was close to the bridge wire, and the current injection test was performed. The relationship between the bridge wire temperature rise and the injection current was obtained, and the $50 \%$ ignition temperature of the EED was determined. To make the tested EED ignite under the existing conditions, the lead wire of the EED was refitted into a half-wave dipole antenna structure to improve the electric field coupling condition of the EED. According to the Bruceton method [38], the irradiation test of the EED was performed, and the ignition field strength at $50 \%$ ignition of the EED was obtained. Under the same test conditions, the high field electromagnetic environment effect equivalent test was performed to determine the relationship between the irradiation field strength and the bridge wire temperature. According to the ignition temperature of the EED, the equivalent test radiation field intensity of $50 \%$ ignition of the EED was obtained. The radiation field strength obtained by the equivalent test method was compared with that obtained by the direct irradiation method to verify whether the test error of the equivalent test was less than $1 \mathrm{~dB}$.

\section{Theoretical Analysis}

Whether the EED can ignite is determined by the hot-spot temperature of the wrapped explosive, which is closely related to the bridge wire temperature. Under the electromagnetic radiation, the ignition temperature of wrapped explosive is not related to the frequency of the electromagnetic wave [39]; therefore, this study evaluated the ignition field strength of the EED by measuring the temperature rise of the bridge wire. The design process of the equivalent test method for the electromagnetic radiation effect of the EED is illustrated in Figure 1. Under steady conditions, the bridge wire temperature of the mathematical model rise, and the current of the EED is established through the theoretical analysis, and the 50\% ignition current of the EED is obtained through experiment to determine the ignition temperature of the EED. Under the condition of electromagnetic pulse irradiation, the mathematical model of the bridge wire temperature rise and electric field intensity of EED is established. Combined with the ignition temperature of EED, the equivalent irradiation field intensity of EED ignition is determined.

The bridge wire material of the EED applied in the study was nickel-chromium alloy 6J20, which had a significantly low-temperature coefficient of resistance reaching nearly $7 \times 10^{-5} \cdot \mathrm{C}^{-1}$ [39]. In the range of the test error, it can be considered that the resistance of the bridge wire is not altered with the increase in the temperature. The bridge wire on the EED will increase under heat insulation or heat balance.

Under insulation, by complying with the law of energy conservation, the heat generated on the bridge wire was used for the temperature increase in the bridge wire [40], as expressed below:

$$
\int_{0}^{t_{0}} I^{2} R \mathrm{~d} t=c m \Delta T,
$$

where $I$ denotes the current through the bridge wire, $R$ expresses the equivalent impedance of the EED, $t_{0}$ represents the action time, $c$ expresses the specific heat of the bridge wire of the EED, $m$ represents the quality of the bridge wire of the EED, and $\Delta T$ is the temperature increase in the bridge wire of the EED.

Under heat balance, the heat generated by the bridge wire is used for the temperature increase of the bridge wire and is transferred to the external medium. By complying with Fourier's law, the heat loss of the bridge wire is proportional to the temperature gradient perpendicular to the cross section and the cross-sectional area [37] as follows: 


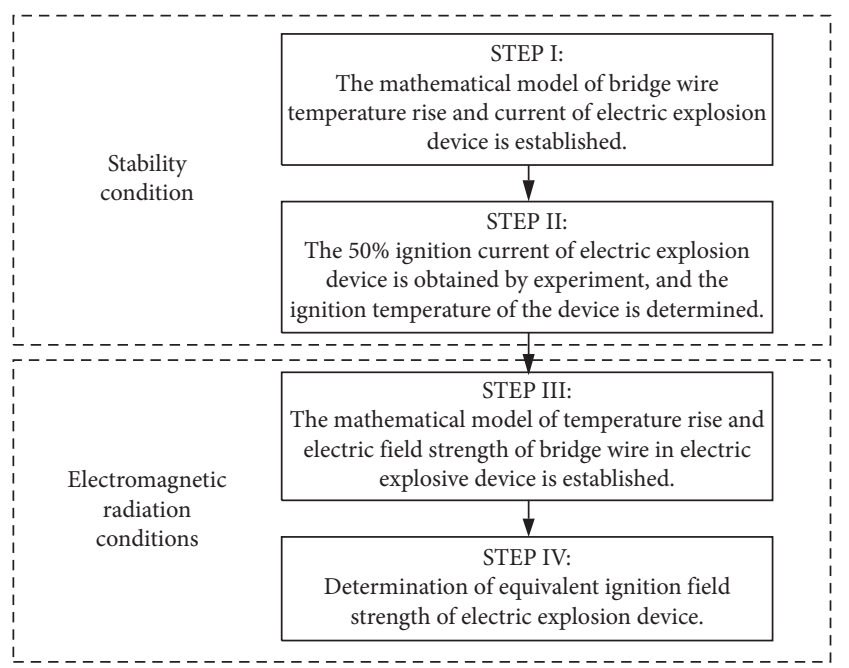

FIGURE 1: The design process of the equivalent test method for electromagnetic radiation effect of EED.

$$
Q^{\prime}=k \frac{\mathrm{d} T}{\mathrm{~d} r} S,
$$

where $Q^{\prime}$ denotes the heat loss of the bridge wire, $k$ expresses the heat transfer coefficient of medium, $\mathrm{d} T / \mathrm{d} r$ represents the temperature gradient perpendicular to the cross section of the bridge wire, and $S$ expresses the cross-sectional area perpendicular to the bridge wire section.

As concluded from the mentioned analysis, the temperature increase of the bridge wire and $\mathrm{d} T / \mathrm{d} r$ are integral relations [37] expressed as follows:

$$
Q^{\prime}=k^{\prime} \cdot \Delta T,
$$

where $Q^{\prime}$ denotes the heat loss of the bridge wire and $k^{\prime}$ expresses the scale factor.

As indicated from equations (1) and (3), the temperature increase of the bridge wire is directly proportional to the square of the current on the bridge wire, whether under adiabatic conditions or thermal equilibrium conditions [41],

$$
\Delta T=p \cdot I^{2},
$$

where $p$ expresses the scale factor.

The following analysis can be obtained: under the condition of stability, the relationship between the temperature of the bridge wire and the injection current of the EED is established. The ignition temperature of the EED is obtained by combining the 50\% ignition current of the EED obtained by the Bruceton method.

The induced electromotive force is defined by the induced electric field on the EED as radiated by the electromagnetic field [42]:

$$
e=\sum_{i=1}^{w} E_{i} \cdot l_{i}
$$

where $w$ expresses the number of sections divided into the leads of the EED, $E_{i}$ represents the strength of the electric field at the nth part lead, and $l_{i}$ is the length of the electric field at the nth part lead.

In the experiment, there was a uniform electromagnetic field near the EED, so $E$ is not associated with the integral circuit [43]. Equation (5) can be simplified as

$$
e=E \cdot l \text {. }
$$

From equations (4) and (6), we can get

$$
\Delta T=q \cdot E^{2},
$$

where $q$ denotes the scale factor.

From the above analysis, we can get the relationship between the temperature rise of the bridge wire and the electric field intensity under the electromagnetic field irradiation. Based on the response characteristics of EED under low field irradiation, the response level of EED under the high power and the high field irradiation is calculated. Combined with the ignition temperature and test environment temperature, the electric field intensity of $50 \%$ ignition of the EED is calculated. The equivalent test method of the low field electromagnetic environment effect of EED provides a technical means for evaluating the safety and survivability of the weapon system in complex electromagnetic environments.

\section{Test Method}

3.1. Test Method for Ignition Excitation of EED under Stable Conditions. Aiming at the high power and high field electromagnetic radiation effect test required by the weapon system, the equivalent test method of the high field electromagnetic environment effect is proposed. Whether the EED can ignite depends on the temperature of the bridge wire. By injecting constant current into the EED, $50 \%$ of the ignition current can be obtained. Then, the temperature rise of the bridge wire under different current injection is tested to determine the relationship between current and bridge wire temperature. Thus, the ignition temperature of the EED is obtained. In order to improve the electromagnetic sensitivity of the EED, the lead of the EED is refitted into a dipole antenna. Under continuous wave irradiation, the relationship between the bridge wire temperature rise and field strength is obtained by irradiating the EED with a low field strength. According to the ignition temperature of the EED obtained from the DC current injection test, the radiation field intensity of the equivalent test of 50\% ignition of the EED is calculated to verify the accuracy and reliability of the ignition field strength obtained by the equivalent test method, and it is necessary to obtain the actual ignition field strength of the EED. Under the same conditions, according to the Bruceton method, the electromagnetic field irradiation test of the EED was carried out, and the ignition field strength of the EED at $50 \%$ ignition was obtained. By 
comparing the difference between the ignition field strength obtained by the whole irradiation method and that obtained by the equivalent test method, it is evaluated whether the test error of the equivalent test method is more than $1 \mathrm{~dB}$. The test flowchart of the equivalent test method for a strong field electromagnetic radiation effect is shown in Figure 2.

On the whole, the test system consisted of DC stable power supply, digital multimeter, two relays, test box, and EED. One output of the DC stable power supply provided the working voltage for the two time relays, and the other output provided the stable current for the EED. For two time relays, one was set to $2 \mathrm{~s}$ normally closed relay, and the other was set to $12 \mathrm{~s}$ normally open relay, which controlled the start and interruption of current on the EED. Two relays controlled the current injection and termination of the EED. One relay's initial state was open and set to close after $2 \mathrm{~s}$; the other relay's initial state was closed and set to open after $12 \mathrm{~s}$. The output current of the DC stable power supply was measured using a digital multimeter. Figure 3 illustrates the schematic diagram of the ignition excitation test system of the EED.

During the test, to prevent the explosion of the EED from jeopardizing people and damaging equipment, a metal box was used as the test box. The EED was placed in the test box for the ignition test. The current injection test was performed on the EED, and the initial excitation current was $180 \mathrm{~mA}$. When the output of the DC stable power supply reached $180 \mathrm{~mA}$ as measured using digital multimeter, the output current would be stopped, and the output current would be switched to the line with EED. The relay started to inject current into the EED after $2 \mathrm{~s}$, and the other relay closed after $12 \mathrm{~s}$ to stop injecting current into the EED. The ignition state and injection current of the EED were observed and recorded. The current step was set to $10 \mathrm{~mA}$, and the test data are listed in Table 1 .

The test data were analyzed with the Bruceton method:

$$
\sum n_{i 1}=15,
$$

where $n_{i 1}$ denotes the ignition number of the sample.

$$
\Delta T=p \cdot I^{2},
$$

where $n_{i 0}$ represents the misfired number of the sample.

$$
n=\sum n_{i}=\sum n_{i 0}=14,
$$

where $n$ expresses the number of valid probes.

$$
\begin{aligned}
A & =\sum\left(i \cdot n_{i}\right)=-8, \\
B & =\sum\left(i^{2} \cdot n_{i}\right)=16, \\
M & =\frac{n \cdot B-A^{2}}{n^{2}} \approx 0.82, \\
b^{\prime} & =\left|\frac{A}{n}-\frac{1}{2}\right|-\left[\left|\frac{A}{n}-\frac{1}{2}\right|\right] \approx 0.1 .
\end{aligned}
$$

When $b^{\prime} \leq 0.5$,

$$
b=b^{\prime}=0.1 \text {, }
$$

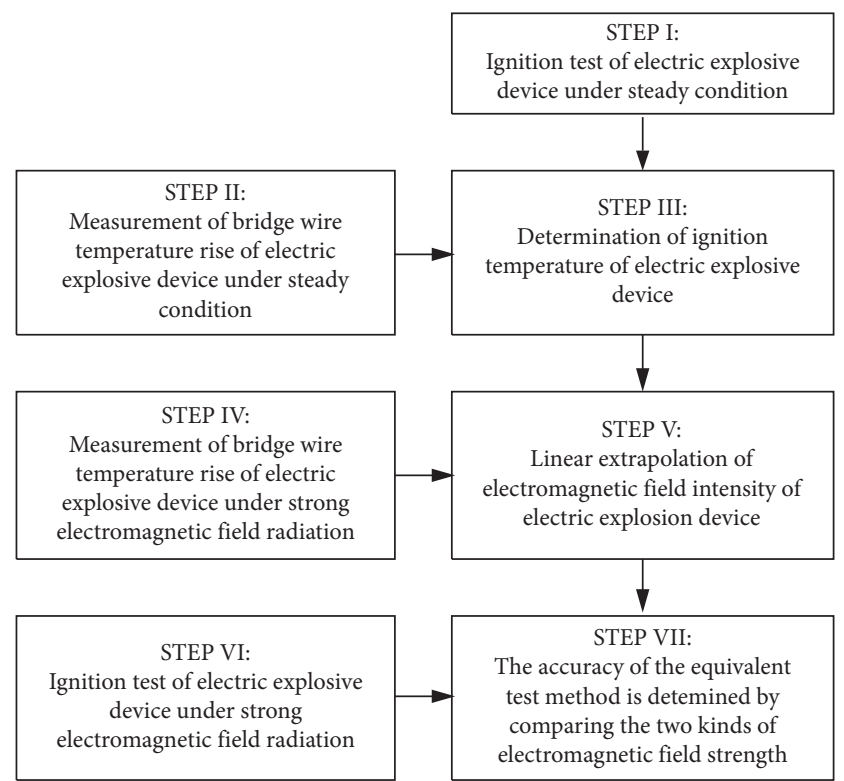

Figure 2: Test flowchart of the equivalent test method for strong field electromagnetic radiation effect.

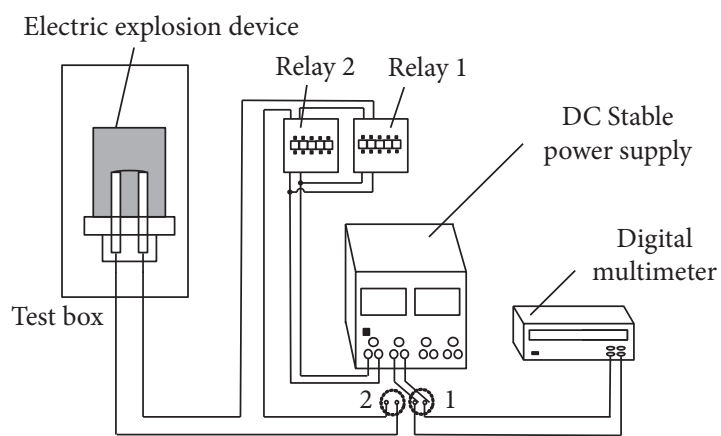

Figure 3: Schematic diagram of the ignition excitation test system for EED.

where $A, B, M, b^{\prime}$, and $b$ are the median values adopted to calculate $50 \%$ ignition electrical excitation and assess the standard deviation.

The $50 \%$ igniting voltage estimate value $\mu$ of the tested sample is expressed as

$$
\mu=y_{0}+\left(\frac{A}{n} \pm \frac{1}{2}\right) \cdot \delta=189.3
$$

where $y_{0}$ denotes the current of the first test stimulation and $\delta$ represents the step value of the injection current increase or decrease. $n$ form (8) and (10), $\sum n_{i 1} \leq \sum n_{i 0}, n=\sum n_{i 1}$, in equation (9) “ \pm " is “-," $\sum n_{i 1}>\sum n_{i 0}, n=\sum n_{i 0}$, in equation (9) “ \pm "is "+."

Based on the calculation of results of $n, M$, and $b$, from the appendix of GJB/Z 377A-94, it yields

$$
\begin{aligned}
\rho & =\rho(29,0.82,0.1)=1.489, \\
G & =G(\rho, b)=0.962, \\
H & =H(\rho, b)=1.570,
\end{aligned}
$$

where $\rho, G$, and $H$ are the median values. 
TABLE 1: Test data of ignition excitation of EED under stable conditions.

\begin{tabular}{|c|c|c|c|c|c|c|c|c|c|c|c|c|c|c|c|c|c|c|c|c|c|c|c|c|c|c|c|c|c|c|}
\hline$I(\mathrm{~mA})$ & $i$ & 1 & 2 & 3 & 4 & 5 & 6 & 7 & 8 & 9 & 10 & 11 & 12 & 13 & 14 & 15 & 16 & 17 & 18 & 19 & 20 & 21 & 22 & 23 & 24 & 25 & 26 & 27 & 28 & 29 \\
\hline 170 & 2 & & & & & & & & & & & & & & & 0 & & 0 & & & & & & & & & & & & 0 \\
\hline 180 & 1 & & & & & & 0 & & & & & & 0 & & 1 & & 1 & & 0 & & & & & & & & & & 1 & \\
\hline 190 & 0 & 0 & & 0 & & 1 & & 0 & & 0 & & 1 & & 1 & & & & & & 0 & & 0 & & & & 0 & & 0 & & \\
\hline 200 & -1 & & 1 & & 1 & & & & 1 & & 1 & & & & & & & & & & 1 & & 0 & & 1 & & 1 & & & \\
\hline 210 & -2 & & & & & & & & & & & & & & & & & & & & & & & 1 & & & & & & \\
\hline
\end{tabular}

$i$ is the weight coefficient; 0 means that the sample is not changed, and 1 means the sample exploded.

Standard deviation estimate value $\sigma$ is given as follows:

$$
\sigma=\rho \cdot d=14.89 \text {. }
$$

3.2. Test Method for Ignition Temperature Increase of EED under Stable Conditions. The schematic diagram of the bridge wire temperature increase test system on the EED is illustrated in Figure 4. One output of the DC stable power supply provided the working voltage for the two time relays, and the other output provided the stable current for the EED. For two time relays, one was set to 2 s normally closed relay, and the other was set to $12 \mathrm{~s}$ normally open relay, which controlled the start and interruption of current on the EED. Two relays controlled the current injection and stop of the EED. One relay's initial state was open and set to close after $2 \mathrm{~s}$; the other relay's initial state was closed and set to open after $12 \mathrm{~s}$. The output current of the DC stable power supply was measured using a digital multimeter. The temperature sensor probe was employed to measure the temperature increase of the bridge wire on the EED, and it was connected with the data acquisition card through the optical fiber to display the temperature increase reading on the computer.

The lines were connected according to the schematic diagram of the test system, and the test system was built. The digital multimeter was adopted to measure the output of DC stable power supply. When the output current reached $20 \mathrm{~mA}$, the current output would be stopped. The electric current was applied to the circuit of the EED for removing the explosive, the power switch was turned on, the relay closed after $2 \mathrm{~s}$, and the injection of current would be started into the EED. After $12 \mathrm{~s}$, another relay opened, and current injection was stopped. The current step was set to $10 \mathrm{~mA}$, and the temperature increase corresponding to the optical fiber temperature measurement system was recorded when different currents were being injected into the EED following the above steps.

As the temperature of the test sensor exceeds $150^{\circ} \mathrm{C}$, the temperature probe will be burned. When the temperature increase of the probe reaches about $100^{\circ} \mathrm{C}$, the test is stopped. The test data of the bridge wire temperature increase of the EED are listed in Table 2.

According to the test results, the relationship between the bridge wire temperature increase and the square of the injection current was drawn (Figure 5). The relationship between the bridge wire temperature increase and the injection current was obtained by combining with equation (4):

$$
\Delta T=0.01 \cdot I^{2}
$$

As revealed from the ignition current and equation (16), the temperature increase of the bridge wire is $357.2^{\circ} \mathrm{C}$ when the EED is ignited, and the temperature of the bridge wire is $382.1^{\circ} \mathrm{C}$ under the $50 \%$ ignited EED.

3.3. Test Method for Ignition Excitation of EED under Electromagnetic Field. To determine the 50\% ignition field strength of EED as radiated by the strong electromagnetic field, the ignition test system of the EED as radiated by the strong electromagnetic field was designed, and the test schematic diagram is presented in Figure 6. The continuous wave signal of $300 \mathrm{MHz}$ from the RF signal generator was amplified with a broadband power amplifier. The amplified continuous wave signal enters the stacked logarithmic antenna, and the EED is placed in the far field of the biconical antenna for $50 \%$ ignition test. In order to improve the degree of electromagnetic coupling, the leads at both ends of the EED are modified. The continuous wave wavelength of $300 \mathrm{MHz}$ is $1 \mathrm{~m}$, corresponding to the maximum coupling antenna length of $0.5 \mathrm{~m}$. Therefore, the continuous wave irradiation test is carried out after the lead of the EED is modified to $0.5 \mathrm{~m}$. The polarization direction of the continuous wave is vertical polarization, so the lead of the modified EED is placed perpendicular to the ground for the test. By regulating the output signal of the RF signal generator, the RF signal with different intensities could be transmitted, and the field strength near the fixed platform of the tested EED was measured using a field strength meter.

The test system was built by complying with the test schematic diagram of the EED as radiated by the strong electromagnetic field. The EED was fixed on the fixing bracket of the EED. The distance between the center of the stacked logarithmic antenna and the center of the fixed bracket of the tested EED was fixed to $d$. The RF signal generator, the broadband power amplifier, the dual channel microwave power meter, and the electromagnetic field strength tester were turned on successively. The output RF signal of the RF signal generator was adjusted to observe whether the EED was ignited. Then, the field strength meter was employed to test the field strength close to the tested EED. The radiation field intensity tended to increase according to the principle of equal step till the EED was ignited. The effective test started from the first time when the test result changed and was counted. Each test should replace a novel EED, and the irradiation time shall be set to $2 \mathrm{~s}$. 


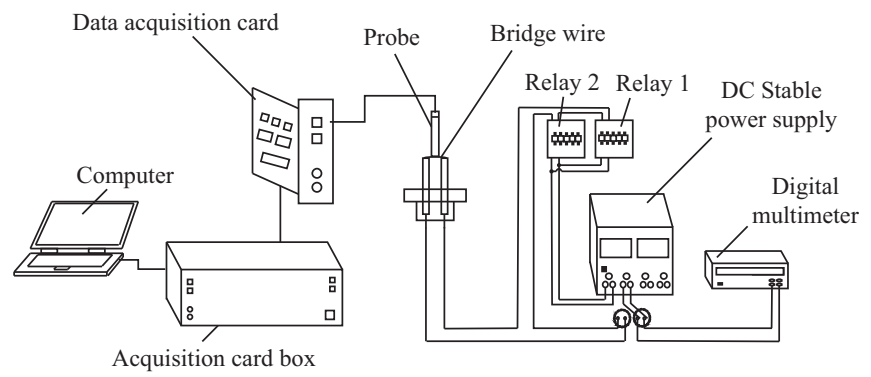

FIGURE 4: Schematic diagram of the bridge wire temperature increase test system.

TABLE 2: Test results of bridge wire temperature increase at ambient temperature of $25.6^{\circ} \mathrm{C}$.

\begin{tabular}{|c|c|c|c|c|c|c|c|c|c|}
\hline Injection current (mA) & 20.3 & 29.9 & 39.7 & 49.7 & 59.8 & 69.0 & 79.7 & 89.6 & 100.4 \\
\hline Temperature increase of bridge wire $\left({ }^{\circ} \mathrm{C}\right)$ & 4.7 & 10.2 & 17.7 & 25.7 & 38.8 & 51.2 & 66.3 & 81.4 & 103.8 \\
\hline
\end{tabular}

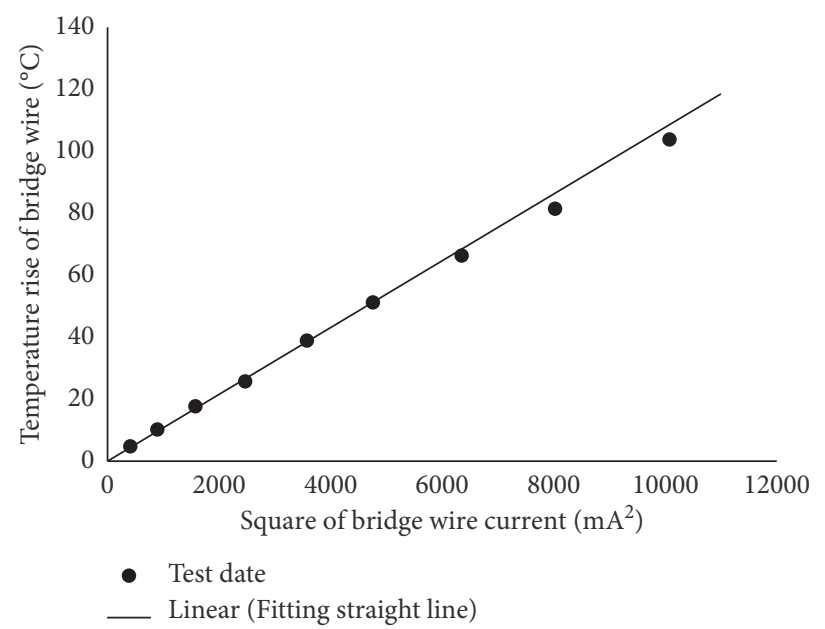

FIGURE 5: Relationship between temperature increase of the bridge wire and square of injection current.

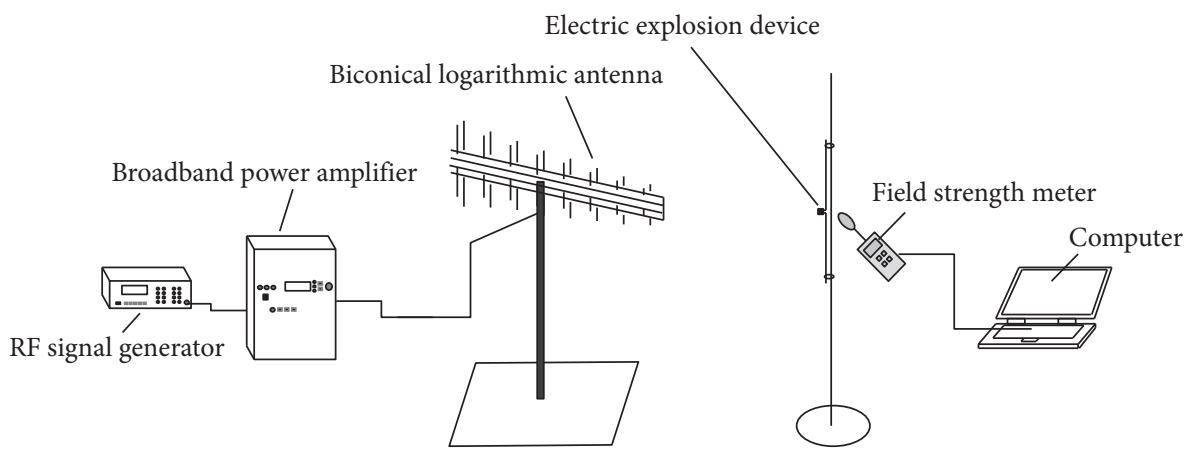

FIgURE 6: Schematic diagram of the EED ignition excitation under electromagnetic field.

The reading of the field strength meter was recorded. If the EED was ignited, the ignited one was recorded as "1," and the nonignited one was recorded as " 0 ." The test results are listed in Table 3.

3.4. Test Method for Ignition Temperature Increase of EED under Electric Field Intensity. To determine the relationship between the temperature increase and the electric field intensity of the bridge wire of the EED as radiated by the strong electromagnetic field, the temperature increase test system of the EED as radiated by the strong electromagnetic field is designed, and the test schematic diagram is shown in Figure 7.

The test system was set up based on the prediction schematic diagram of the bridge wire ignition temperature increase of the EED as radiated by the strong electromagnetic field. The EED for removing the explosive was fixed on the bracket. The distance between the center of the stacked 
TABLE 3: Ignition excitation test data of EED under continuous wave at $300 \mathrm{MHz}$.

\begin{tabular}{|c|c|c|c|c|c|c|c|c|c|c|c|c|c|c|c|c|c|c|c|c|c|c|c|c|c|c|c|c|c|c|}
\hline$E(\mathrm{~V} / \mathrm{m})$ & $i$ & 1 & 2 & 3 & 4 & 5 & 6 & 7 & 8 & 9 & 10 & 11 & 12 & 13 & 14 & 15 & 16 & 17 & 18 & 19 & 20 & 21 & 22 & 23 & 24 & 25 & 26 & 27 & 28 & 29 \\
\hline 85 & 3 & & & & & & & & & & & & & & & & & & & & & & & 0 & & & & & & \\
\hline 95 & 2 & & & & & & & & & & & & & & & & & & & & & & 1 & & 0 & & & & & \\
\hline 105 & 1 & & & & & & & & & & & & & & & & & 0 & & 0 & & 1 & & & & 0 & & & & \\
\hline 115 & 0 & & & & & & & & & & 0 & & 0 & & 0 & & 1 & & 1 & & 1 & & & & & & 0 & & & \\
\hline 125 & -1 & & & & & 0 & & & & 1 & & 1 & & 1 & & 1 & & & & & & & & & & & & 0 & & 0 \\
\hline 135 & -2 & & 0 & & 1 & & 0 & & 1 & & & & & & & & & & & & & & & & & & & & 1 & \\
\hline 145 & -3 & 1 & & 1 & & & & 1 & & & & & & & & & & & & & & & & & & & & & & \\
\hline
\end{tabular}

The test data were analyzed by the Bruceton method and combined with equations (8)-(12). $E_{0}=115 \mathrm{~V} / \mathrm{m}, d=10 \mathrm{~V} / \mathrm{m}, n=14, A=-1, B=27, M=1.9$, and $b=0.1$. The $50 \%$ ignition field strength of EED is calculated: $E_{50}=115.0 \mathrm{~V} / \mathrm{m}$. Standard deviation: $\sigma=39.8 \mathrm{~V} / \mathrm{m}$.

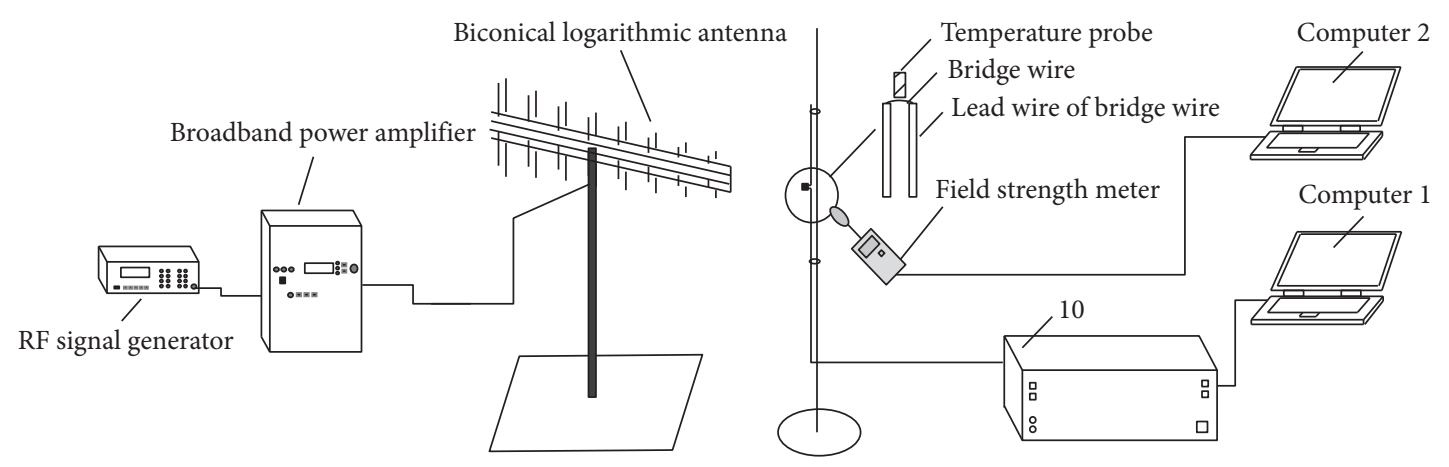

FIgURE 7: Schematic diagram of the bridge wire temperature rise test of EED under strong electromagnetic field.

TABLE 4: Test results of the bridge wire temperature increase under strong electromagnetic field at ambient temperature of $32.2^{\circ} \mathrm{C}$.

\begin{tabular}{lcccccc}
\hline Electric intensity $(\mathrm{V} / \mathrm{m})$ & 19.6 & 29.4 & 39.2 & 49.0 & 58.8 & 68.7 \\
\hline Temperature increase of bridge wire $\left({ }^{\circ} \mathrm{C}\right)$ & 9.5 & 28.2 & 49.3 & 78.2 & 108.9 & 136.4 \\
\hline
\end{tabular}

log periodic antenna and the center of the fixed bracket of the tested EED was fixed as $d$. The continuous wave signal of $300 \mathrm{MHz}$ from the RF signal generator was amplified with the broadband power amplifier, and the amplified continuous wave signal entered the log periodic antenna to perform the temperature increase test of the bridge wire of the EED as radiated by the strong electromagnetic field. By adjusting the RF signal generator to change the electric field radiation intensity, the field intensity close to the EED was determined using the field intensity meter. The electric field radiation intensity increased gradually according to the principle of equal step size, and the exposure and rest time of EED are $5 \mathrm{~s}$ and $30 \mathrm{~s}$, respectively, at each level of applied electric field using the RF source. The test data were tested and recorded (Table 4).

According to the test data, the relationship between the bridge wire temperature increase and the square of electric field intensity is drawn at $300 \mathrm{MHz}$, as shown in Figure 8.

According to equation (7), the relationship model between the temperature increase of the bridge wire and the radiation field intensity is obtained:

$$
\Delta T=0.03 \cdot E^{2} .
$$

From $50 \%$ ignition temperature, $382.1^{\circ} \mathrm{C}$ under stable condition, and combined with equation (16), the ignition field strength of electromagnetic radiation equivalent test of EED is $108.0 \mathrm{~V} / \mathrm{m}$.

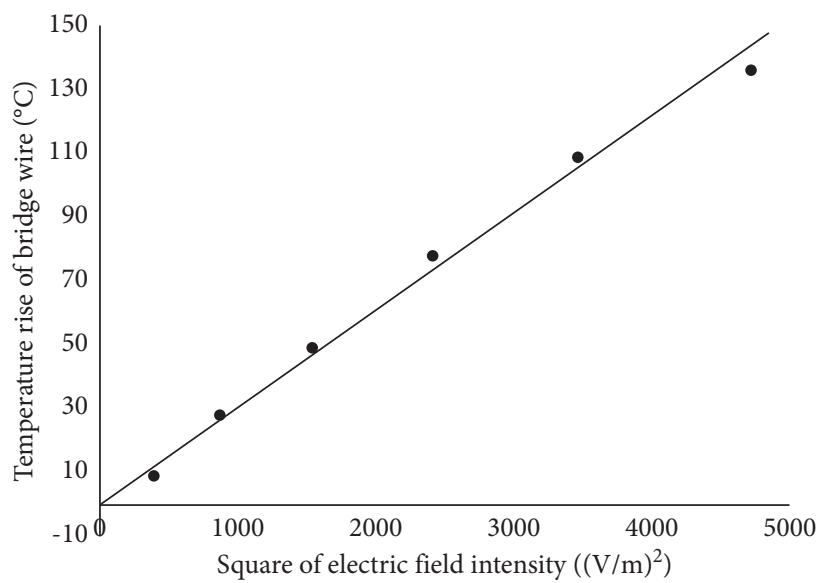

FIGURE 8: Relationship between the temperature increase of bridge wire and square of electric field intensity at $300 \mathrm{MHz}$.

According to the equivalent test method of strong electromagnetic field radiation effect of EED, the ignition field strength is obtained, and the ignition field strength E50 of the whole irradiation method is obtained. Test error $\delta$ of the equivalent test method is calculated as

$$
\delta=20 \cdot \log E-20 \cdot \log E_{50} .
$$


The results show that the error is only $-0.55 \mathrm{~dB}$ when the ignition field strength obtained by the two methods is brought into formula (17). Thus, the feasibility and accuracy of the equivalent test method are verified, which provides test methods and technical means for the safety assessment of the weapon system electromagnetic environment, and is of great significance in the improvement of the safety and survivability of the weapon system in complex electromagnetic environments.

\section{Conclusions}

At present, the weapon system faces the complex electromagnetic environment of high power and high field strength, and the existing test system and test method cannot meet its safety performance test. This paper presents an equivalent test method of low field strength for EED. Through the theoretical analysis and test, according to the equivalent test method of EED, the ignition field strength is determined to be $108.0 \mathrm{~V} / \mathrm{m}$. Under the same conditions, according to the Bruceton method, the ignition field strength of $50 \%$ ignition is $115.0 \mathrm{~V} / \mathrm{m}$. By comparing the difference between the ignition field strength obtained by the whole irradiation method and that obtained by the equivalent test method, the test error of the equivalent test method is determined to be $-0.55 \mathrm{~dB}$, which verifies the feasibility and accuracy of the equivalent test method of the EED.

This paper presents an equivalent test method for electromagnetic field radiation effect of EED, which solves the problem that the electromagnetic environment effect test cannot be completed due to insufficient test conditions. It provides the test method and technical support for the electromagnetic environment effect test of the weapon system under high power and high field strength. It is critical to improve the safety and survivability of the weapon system in complex electromagnetic environments.

\section{Data Availability}

The data used to support the findings of this study are included within the article.

\section{Conflicts of Interest}

The authors declare that there are no conflicts of interest regarding the publication of this study.

\section{Acknowledgments}

The authors would like to acknowledge National Defense Equipment Advance Research Program of China (Grant no. 61402090301) and Key Basic Research Projects of Basic Strengthening Plan of China (Grant no. 2017-JCJQ-ZD-004) for providing fund for conducting the experiments.

\section{References}

[1] B. Bergman, "Safety assessment of electro-explosive devices," Reliability Engineering, vol. 3, no. 3, pp. 193-202, 1982.
[2] B. Parate, S. Chandel, and H. Shekhar, "Lumped parameter analysis of bridge wire in an electro explosive device of a power cartridge for water-jet application: a case study," Central European Journal of Energetic Materials, vol. 17, no. 3, pp. 408-427, 2020.

[3] J. J. Pantoja, F. Vega, F. Roman, N. Pena, and F. Rachidi, "On the differential input impedance of an electro-explosive device," IEEE Transactions on Microwave Theory and Techniques, vol. 66, no. 2, pp. 858-864, 2018.

[4] J. Pantoja, N. Pena, F. Rachidi, F. Vega, and F. Roman, "Susceptibility of electro-explosive devices to microwave interference," Defence Science Journal, vol. 63, no. 4, pp. 386-392, 2013.

[5] Y. Li, X. Jia, L. Wang, B. Zhou, and R. Shen, "Research on the electro-explosive behaviors and the ignition performances of energetic igniters," Journal of Energetic Materials, vol. 36, no. 1, pp. 1-12, 2018.

[6] W. Ma, J. Lu, and Y. Liu, "Research progress of electromagnetic launch technology," IEEE Transactions on Plasma Science, vol. 47, no. 5, pp. 2197-2205, 2019.

[7] Z. H. Yao, T. Zhao, X. F. Ji, J. H. Chen, and M. Yin, "Electromagnetic compatibility time domain response characteristics of EEDs," Initiators \& Pyrotechnics, vol. 2, pp. 25-28, 2020.

[8] E. Y. Chu, F. Zhang, J. H. Chen, Y. L. Wang, Y. Xue, and R. Z. Xie, "Supplementary discussion of concepts of the 4th generation pyrotechnics," Initiators \& Pyrotechnics, vol. 6, pp. 1-4, 2020.

[9] A. M. Yang, X. Li, D. X. Xia, and H. Z. Yao, "Research of environmental effect of electromagnetic waves on semiconductor initiator," Initiators \& Pyrotechnics, vol. 2, pp. 21-24, 2020.

[10] J. Jun Han, Y. Yuan Pan, and J.-J. Junjia He, "Study of employing railguns in close-in weapon systems," IEEE Transactions on Magnetics, vol. 45, no. 1, pp. 641-644, 2009.

[11] R. E. Johannesen and L. M. Farrell, "PANTEX: Safety in nuclear weapons processing," Health Physics, vol. 79, no. 5, pp. S91-S95, 2000.

[12] F. Czerwinski, "Controlling the ignition and flammability of magnesium for aerospace applications," Corrosion Science, vol. 86, pp. 1-16, 2014.

[13] N. Doerry, J. Amy, and C. Krolick, "History and the status of electric ship propulsion, integrated power systems, and future trends in the U.S. Navy," Proceedings of the IEEE, vol. 103, no. 12, pp. 2243-2251, 2015.

[14] H. D. Fair, "Electromagnetic launch: a review of the U.S. national program," IEEE Transactions on Magnetics, vol. 33, no. 1, pp. 11-16, 1997.

[15] H. D. Fair, "Electromagnetic launch science and technology in the United States enters a new era," IEEE Transactions on Magnetics, vol. 41, no. 1, pp. 158-164, 2005.

[16] I. R. McNab, "Early electric gun research," IEEE Transactions on Magnetics, vol. 35, no. 1, pp. 250-261, 1999.

[17] R. Camilleri and A. J. Vella, "Emission factors for aerial pyrotechnics and use in assessing environmental impact of firework displays: case study from Malta," Propellants, Explosives, Pyrotechnics, vol. 41, no. 2, pp. 273-280, 2016.

[18] J. Cheng, N. Yan, Y. Ye, and F. Zheng, "Stability of pyrotechnic composition in flame detonator exposed to severe thermal stimulus," Chemical Research in Chinese Universities, vol. 31, no. 5, pp. 814-819, 2015.

[19] H. Zhang, K. Dai, and Q. Yin, "Ammunition reliability against the harsh environments during the launch of an 
electromagnetic gun: a review," IEEE Access, vol. 7, pp. 45322-45339, 2019.

[20] Z. Qi, X. Li, H. Li, and W. Liu, "First results from drone-based transient electromagnetic survey to map and detect unexploded ordnance," IEEE Geoscience and Remote Sensing Letters, vol. 17, no. 12, pp. 2055-2059, 2020.

[21] B. W. Bush and R. D. Small, "A note on the ignition of vegetation by nuclear weapons," Combustion Science and Technology, vol. 52, no. 1-3, pp. 25-38, 1987.

[22] Y. Xiao, Y. Li, Z. Wang, H. Zhao, and Y. Sun, "A constitutive model for the shock ignition of polymer bonded explosives," Combustion Science and Technology, vol. 191, no. 3, pp. 590-604, 2019.

[23] Q. Zhang, C. H. Bai, H. Y. Dang, and H. Yan, "Critical ignition temperature of fuel-air explosive," Defence Science Journal, vol. 54, no. 4, pp. 469-474, 2004.

[24] G. Krause, "Volume-dependent self-ignition temperatures for explosive materials," Propellants, Explosives, Pyrotechnics, vol. 37, no. 1, pp. 107-115, 2012.

[25] A. Sharp, J. Andrade, and N. Ruffini, "Design for reliability for the high reliability fuze," Reliability Engineering \& System Safety, vol. 181, pp. 54-61, 2019.

[26] J.-H. Jeong, J. Eom, S. S. Lee et al., "Miniature mechanical safety and arming device with runaway escapement arming delay mechanism for artillery fuze," Sensors and Actuators A: Physical, vol. 279, pp. 518-524, 2018.

[27] US Military Specs, Munition Rocket and Missile Motor Ignition System Design: Safety Criteria, US Military Specs, Washington, D.C, WA, USA, 2002.

[28] Safety criteria for fuze design. USA 2001. ISBN: MIL-STD1316D.

[29] Military Standard Publishing Department of General Equipment Department, Electromagnetic Compatibility Requirements for Systems, Military Standard Publishing Department of General Equipment Department, Beijing, China, 2005.

[30] Military Standard Publishing Department of General Equipment Department, Test Method for Hazards of Electromagnetic Radiation to Ordnanc, Military Standard Publishing Department of General Equipment Department, Beijing, China, 2012.

[31] K. Zhao, Z.-X. Su, J.-R. Liu et al., "Suppression of nonlinear standing wave excitation via the electrical asymmetry effect," Plasma Sources Science and Technology, vol. 29, no. 12, pp. 124001-124011, 2020.

[32] J. Li, Z. Zhou, and P. Hu, "Calculating method for RF induced current of electric-explosive device based on agrawal model and non-uniform transmission line," in Proceedings of the 14th IEEE International Conference on Electronic Measurement \& Instruments (ICEMI), pp. 736-741, Changsha, China, November 2019.

[33] Y. Yu Du and W. Dai, "Capture high-frequency partial inductance more accurately by Gauss quadrature integration with skin-effect model," IEEE Transactions on Microwave Theory and Techniques, vol. 54, no. 3, pp. 1287-1294, 2006.

[34] M. Ghassemi and R. Pasandeh, "Thermal and electromagnetic analysis of an electromagnetic launcher," IEEE Transactions on Magnetics, vol. 39, no. 3, pp. 1819-1822, 2003.

[35] Q. Li, M. Wei, Q.-A. Lv, H.-J. Xiang, and B. Lei, "Simulation on controlled strong magnetic environment for electronic fuze during railguns launching," in Proceedings of the $3 \mathrm{rd}$ International Conference on Information Science and Control Engineering (ICISCE), pp. 1121-1125, Beijing, China, July 2016.
[36] A. E. Bishop and P. Knight, "The safe use of electro-explosive devices in electromagnetic fields," Radio and Electronic Engineer, vol. 54, no. 7-8, pp. 321-335, 1984.

[37] B. Wang, Y. W. Sun, G. G. Wei, X. T. Wang, and H. M. Gao, "Research on test method of ignition temperature of electric explosive device under electromagnetic pulse," Radioengineering, vol. 30, no. 3, pp. 510-516, 2021.

[38] Military Standard Publishing Department of General Equipment Department, Electromagnetic Compatibility Requirements for Systems, Military Standard Publishing Department of General Equipment Department, Beijing, China, 1994.

[39] Y. H. Ye, Technology on Initiating Explosive Device, Beijing Institute of Technology Press, Beijing, China, 2014.

[40] X.-F. Lu, G.-H. Wei, Y.-W. Sun, X. Pan, H. Wang, and B. Wang, "Temperature rise test method of hot bridgewire EED under steady conditions," in Proceedings of the 6th International Symposium on Electromagnetic Compatibility (ISEMC), pp. 1-4, Nanjing, China, November 2019.

[41] T. Zhao, Q.-M. Feng, H.-Z. Yao, and X. F. Ji, "Study on the quantitative test technique of EED induced current," Initiators \& Pyrotechnics, vol. 5, pp. 50-52, 2013.

[42] W.-L. Stutzman and G.-A. Thiele, Antenna Theory and Design, Wiley Publishing, Inc., Hoboken, NJ, USA, Second edition, 2014.

[43] R. Q. Yan, Basis of Microwave Technology, Beijing Institute of Technology Press, Beijing, China, 2004. 